

\title{
Determinants of HIV serostatus disclosure and assessment of the competence of health care personnel in HIV serostatus disclosure
}

\section{Adekunle $\mathrm{MO}^{* 1}$, Olutekunbi $\mathrm{OA}^{2}$, Animasahun BA ${ }^{3}$, Afadapa MA1, Ubuane PO $^{1}$}

\author{
${ }^{1}$ Department of Paediatrics, Lagos State University Teaching Hospital, Ikeja, Lagos, Nigeria \\ ${ }^{2}$ Massey Street Children's Hospital, Lagos Island, Lagos, Nigeria \\ ${ }^{3}$ Department of Paediatrics and Child Health, Lagos State University College of Medicine, Ikeja, Lagos, Nigeria
}

*Correspondence: Dr. MO Adekunle, Department of Paediatrics, Lagos State University Teaching Hospital, 1-5

Oba Akinjobi Lane, Ikeja, Lagos, Nigeria. Email: motunbamm@yahoo.com ;

ORCID - http://orcid.org/0000-0003-2820-3948

\begin{abstract}
Background: Disclosure of HIV serostatus is essential for the care and eradication of HIV infection. The World Health Organization recommends disclosure to school-age children and younger children but this practice is commonly hindered by stigmatization and other presumed psychosocial effects of the disease.

Objective: To identify limitations to the disclosure of serostatus in HIV-infected children, outcomes of disclosure as well as compare the outcomes of disclosure by either parents/caregiver only with the involvement of health care personnel.

Methods: A questionnaire-based study of primary caregivers of children aged 6 years to 18 years with HIV infection who were enrolled at two government-owned tertiary institutions in Lagos State, Nigeria. The healthcare personnel directly involved in the care of these children also participated in the study.

Results: A total of 190 primary caregivers participated in the study. In all, 29 health care personnel completely filled the questionnaires. Disclosure (partial and full) was recorded among 31.0\%. Older children and children with single parents were more likely to know their HIV status. Similar positive and negative impacts of disclosure were observed irrespective of the individuals involved in the processes. In all, $62.1 \%$ of healthcare personnel have had training on disclosure.

Conclusion: Disclosure rate in HIV-infected children was low. There is a need for more training of health personnel and education of caregivers on the benefits of disclosure as well as the introduction of effective measures to tackle the barriers to disclosure.
\end{abstract}

Keywords: Childhood, Disclosure, Healthcare Personnel, Human Immunodeficiency Virus, Lagos. 


\section{Introduction}

Improvement in access to antiretroviral drugs has made HIV infection a chronic disease.[1] Unlike other chronic diseases, discrimination and stigmatization are major consequences of HIV infection which hinder HIV serostatus disclosure. [2] Disclosure of HIV serostatus is crucial to the continuum of care and eradication of HIV infection. [3] Hindrances to the disclosure of HIV serostatus in sub-Saharan Africa are a major factor for its high burden. In Nigeria, 170,000 adolescents are living with HIV and only $12 \%$ of persons within this age group know their HIV status in the country. ${ }^{[4,5]}$ Lack of disclosure of HIV serostatus amongst persons of the age group who are likely to practise unsafe sexual practices will inadvertently contribute to the risk of further spread and impact of HIV infection.

Reports have shown that age-appropriate disclosure of HIV serostatus is beneficial. It increases adherence to medications, access to care and reduces the death rate. However, stigmatization and fear of psychosocial harm are some of the reasons parents refuse to disclose HIV serostatus to their wards. ${ }^{[6]}$

The World Health Organization recommends disclosure to school-age children and younger children using age-appropriate information provision and full disclosure when the child is emotionally matured to receive the information. ${ }^{[6]}$ In addition to determining age, limitation and disclosure outcomes as done in previous studies, this study aimed to compare the outcomes of serostatus disclosure by either parents/caregiver alone with those that involved health care personnel. This will help in suggesting individuals that should be involved in serostatus disclosure to children with HIV infection.

The objective of this study was to evaluate the determinants and effects of serostatus disclosure in children with HIV infection and assess the competence of health care personnel on disclosure of HIV serostatus in HIV Clinics in Lagos state, Nigeria.

\section{Methods}

\section{Study Design}

This was a questionnaire-based study of the caregivers of HIV-infected children. It also included health personnel directly involved in the care of these children.

\section{Study Setting, Population and Duration:}

The study was done in the two tertiary Government institutions in Lagos State (Lagos State University Teaching Hospital (LASUTH), Ikeja and Massey Children's Hospital $(\mathrm{MCH})$, Lagos Island). The two facilities have wellestablished clinics for children with HIV infection.

The study population comprised of caregivers of HIV-infected children aged six years to 18 years who volunteered to partake in the study. It also involved the health personnel (doctors, nurses, and counsellors who primarily cared for children with HIV infection) who consented to partake in the study. The caregivers of children enrolled in the HIV Clinics were consecutively recruited until the desired sample sizes were met (which was determined based on the number of registered children in each study centre). Only HIV-infected children with encephalopathy were excluded from the study. The study was carried out over a three-month period (January to March 2018).

\section{Tool Validation}

Identification of items clarity was done by administering the questionnaire to ten people followed by a pilot study that involved thirty people.

Content validity was assessed by a review of the questionnaire by expertise which included an 
epidemiologist and specialist in Infectious Diseases.

Test-retest for tool internal consistency was done for the caregiver and the health personnel by administering the same questionnaire to ten of them and similarity in responses was observed. The Cronbach's alpha coefficient was 0.85 and 0.70 for the health personnel and the caregivers respectively. Partial disclosure was defined as telling a child about the disease without using the word "HIV or AIDS" while full disclosure was defined as the use of the word HIV or AIDS while explaining the disease to the HIV-infected child. ${ }^{[6]}$ Non-disclosure was described as a lack of awareness about his or her HIV status, the reasons for daily medication or clinic visits.

Socioeconomic Class: The classification of caregivers into different socio-economic classes was done using the model recommended by Ogunlesi et al. [7] The subjects were classified into upper, middle and lower socio-economic classes.

Ethical Consideration: Ethical approval for the study was obtained from the Health Research and Ethics Committee of Lagos State University Teaching Hospital, Ikeja (NHREC04/04/2008).

\section{Data Analysis}

The socio-demographic, anthropometric, clinical data and the responses to the questions were analysed using the Statistical Package for Social Sciences (SPSS) version 20 (IBM Inc., Chicago, USA).

Descriptive and inferential statistics were conducted using the Chi-Square test, Fisher's Exact test, and logistic regression analysis. Probability values less than 0.05 at $95 \%$ confidence interval were considered statistically significant.

\section{Results}

A total of 190 primary caregivers of HIVinfected children participated in the study (150 from LASUTH and 40 from $\mathrm{MCH}$ ). In both centres, most of the caregivers surveyed were mothers $(68.7 \% ; n=103$ in LASUTH and $65 \%$; $n$ $=26$ in $\mathrm{MCH}$ ).

The age ranged from 6 years and 18 years with a mean age of $10.7 \pm 2.9$ years. The mean age of the children at $\mathrm{MCH}$ and LASUTH was 11.6 \pm 3.9 years and $10.5 \pm 2.6$ years respectively $(t=-2.314$, $\mathrm{p}<0.001)$. In all, $114(60 \%)$ of the children were males; majority of the subjects in both centres were also males respectively $(52.5 \% ; \mathrm{n}=21$ and $62 \% ; \mathrm{n}=93$ ).

Disclosure of HIV status (partial and full) of the affected children to them had been done for 14 $(35 \%)$ and $45(30 \%)$ of subjects at $\mathrm{MCH}$ and LASUTH respectively. Full disclosure was done for 10 out of $40(25.0 \%)$ and 39 out of $150(26 \%)$ of the children disclosed to at $\mathrm{MCH}$ and LASUTH respectively.

The minimum and maximum age at serostatus disclosure were 6 years and 16 years respectively. The mean age at serostatus disclosure to affected children was $11.1 \pm 2.3$ years. Children attending LASUTH had a significantly lower mean age at disclosure compared to those attending MCS $(10.5 \pm 1.9$ years vs. $13.1 \pm 2.6$ years; $t=-3.718, p=0.06)$. For children who were yet to have HIV serostatus disclosure, the caregivers intended disclosing between the age range of 8-21 years with a mean age of planned disclosure of $14.2 \pm 3.1$ years. The caregivers of children attending LASUTH had a lower mean age they intended to disclosure the wards' HIV serostatus to them compared to those attending $\mathrm{MCH} \quad(13.3 \pm 2.5$ years vs. $16.2 \pm 3.2$ years; $t=-5.137, \mathrm{p}=0.62)$.

Individuals involved in the disclosure and the effect of disclosure

The disclosure of HIV serostatus to affected children was mostly done by the mothers 
$(35.6 \% ; n=21)$. The fathers solely disclosed to their wards in $9(15.2 \%)$ cases. Both parents were involved in the disclosure to only $2(3.4 \%)$ children. The effect of disclosure was observed among 55 (93.2\%) out of the 59 subjects that had disclosure. No significant difference was observed in responses to the disclosure and individuals involved in disclosing as shown in Table I.

Table I: Relationship between types of individuals involved in serostatus disclosure and the types of responses obtained

\begin{tabular}{|c|c|c|c|c|c|}
\hline \multirow[b]{2}{*}{ Responses to disclosure } & \multicolumn{5}{|c|}{ Individuals involved in sero-status disclosure } \\
\hline & $\begin{array}{l}\text { Parents } \\
(\%)\end{array}$ & $\begin{array}{l}\text { Relatives } \\
(\%)\end{array}$ & $\begin{array}{l}\text { Caregiver with } \\
\text { healthcare } \\
\text { personnel } \\
(\%)\end{array}$ & $\begin{array}{l}\text { Healthcare } \\
\text { personnel only } \\
(\%)\end{array}$ & Total $(\%)$ \\
\hline Positive & $16(44.4)$ & $8(22.2)$ & $4(11.1)$ & $8(22.2)$ & $36(100)$ \\
\hline Negative & $8(72.7)$ & $0(0)$ & $1(9.1)$ & $2(18.2)$ & $11(100)$ \\
\hline No response & $2(50)$ & $0(0)$ & $0(0)$ & $2(50)$ & $4(100)$ \\
\hline $\begin{array}{l}\text { Both positive and } \\
\text { negative }\end{array}$ & $6(75)$ & $0(0)$ & $1(12.5)$ & $1(12.5)$ & $8(100)$ \\
\hline Total & $32(54.2)$ & $8(13.5)$ & $6(10.2)$ & $13(22.0)$ & $59(100)$ \\
\hline
\end{tabular}

Out of 44 children that had positive responses to disclosure, better adherence to medication $(79.5 \% \mathrm{n}=35)$, better relationship with caregiver $(13.6 \% ; \mathrm{n}=6)$ and less frequent questioning $(2.3 \% ; \mathrm{n}=1)$ were the observed responses. In 2 $(4.5 \%)$ children, a combination of better adherence to ARVs and better relationships with caregivers was observed.

Negative responses to disclosure were observed in a total of $19(32.2 \%)$ children. Anger $(52.6 \%$; n $=10)$, withdrawal $(21.0 \% ; n=4)$, sadness $(5.3 \%$; $\mathrm{n}=1)$, loss of trust $(10.5 \% ; \mathrm{n}=2)$, fear $(5.3 \% ; \mathrm{n}=$ $1)$ and questioning the source $(5.3 \% ; n=1)$ were the various negative impacts responses recorded.

The duration of negative responses was reported by $17(89.5 \%)$ out of 19 subjects. The majority of negative responses were observed for less than one week $(64.7 \%$; $n=11)$. In 4 children $(23.5 \%)$, these impacts lasted between one week and a month while in 1 (5.9\%) child, it lasted longer than a month but less than a year.
In one other child, the caregiver observed this impact for over a year (5.9\%).

\section{Reasons for Disclosure and non-disclosure}

The maturity of affected children was the most frequent reason for serostatus disclosure $(28.8 \%$; $\mathrm{n}=17$ ) as shown in Figure 1 . The reasons for serostatus disclosure in $5(8.5 \%)$ cases were multiple including maturity, frequent questioning and poor drug adherence to antiretroviral therapy.

The commonest reasons for HIV serostatus nondisclosure to HIV-infected children included being too young $(56.5 \% ; \mathrm{n}=74)$ and risk of stigmatization $(31.3 \%, \mathrm{n}=41)$ as shown in Figure 2. A combination of children who were considered too young and stigmatization was observed in $2(1.5 \%)$ children.

\section{Healthcare Personnel and HIV disclosure}

A total of 29 health care personnel (8 from MSCH and 21 from LASUTH) who were primarily involved with the care of HIV- 
infected children were surveyed. These included 17 doctors, 7 counselors, and 5 nurses. The median duration of practice was 84 months (IQR 24months, months).

\section{Reasons for HIV status disclosure}

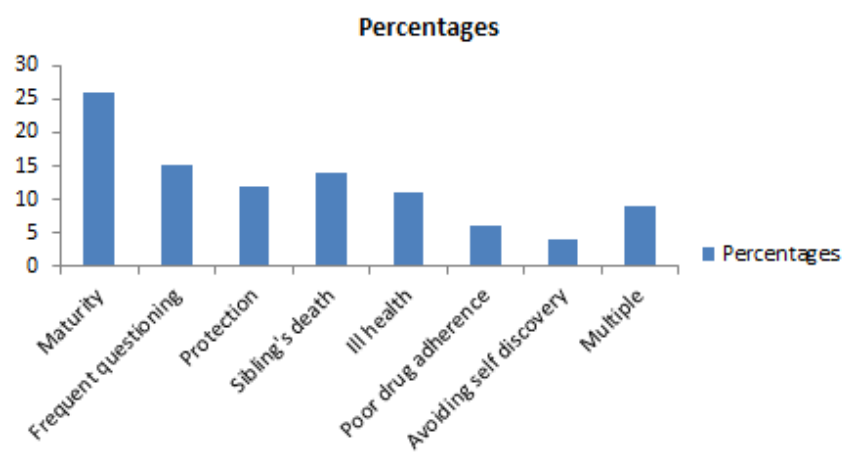

Figure 1: Reasons for HIV serostatus disclosure

\section{Reasons for non-disclosure of HIV status}

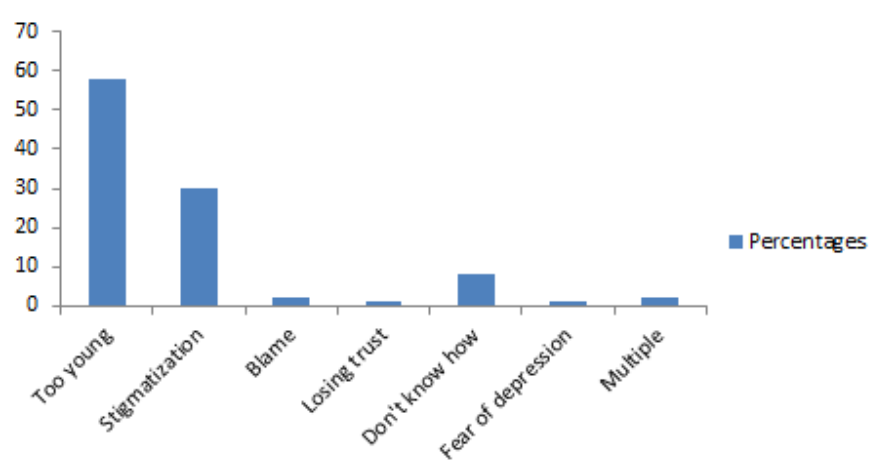

Figure 2: Reasons for HIV serostatus non-disclosure

The mean age expected for serostatus disclosure by healthcare providers was $11.2 \pm 4.5$ years. The majority believed serostatus disclosure should be done at age twelve years and above $(\mathrm{n}=10$; $34.5 \%)$. A total of $5(17.2 \%)$ and $6(20.7 \%)$ health workers expected serostatus disclosure to be done between 5 and 6 years and between 7 and 12 years respectively. Over a quarter $(\mathrm{n}=8$;
$27.6 \%)$ of them had no idea on when serostatus disclosure should be done in HIV-infected children.

In all, $18(62.1 \%)$ healthcare workers have had training on how to disclose HIV serostatus to affected individuals. Majority of individuals with training on disclosure were recruited from 
MSCH $(87.5 \% ; n=7$ vs $52.4 \% ; n=11)$. The need for routine training on disclosure was strongly recommended by the majority $(72.4 \%)$ of the health care personnel. When counseled to disclose the serostatus of HIV-infected children to them, the commonest reasons caregivers gave for negative responses included the inability to keep information, stigmatization and being too young to understand.
Determinants of HIV status disclosure

Table II shows the determinants of serostatus disclosure to affected children. Adolescents (10 to 18 years) were more likely to know their HIV status compared to the younger ones.

Multivariate logistic regression tests showed that the child's age and caregiver's marital status are independent determinants of disclosure as $\begin{array}{lll}\text { shown in } & \text { Table }\end{array}$

Table IIa: Determinants of HIV sero-status disclosure

\begin{tabular}{|c|c|c|c|}
\hline & \multicolumn{2}{|c|}{ HIV Status Disclosure } & \multirow[t]{2}{*}{ Statistics } \\
\hline & No $(\%)$ & Yes (\%) & \\
\hline Age Group (years) & & & $x^{2}=41.606 ; p=0.001$ \\
\hline 6 to $<10$ & $87(66.9)$ & $10(16.9)$ & \\
\hline 10 to 18 & $43(33.1)$ & 49 (83.1) & \\
\hline \multicolumn{4}{|l|}{ Gender } \\
\hline Male & $76(58.0)$ & $38(64.4)$ & $x^{2}=0.692 ; p=0.405$ \\
\hline Female & $55(41.9)$ & $21(35.6)$ & \\
\hline \multicolumn{4}{|l|}{ Social Class } \\
\hline Upper & $30(22.9)$ & $12(20.3)$ & $\chi^{2}=6.259 ; p=0.043$ \\
\hline Middle & $40(30.5)$ & 9 (15.3) & \\
\hline Lower & $61(46.6)$ & $38(64.4)$ & \\
\hline \multicolumn{4}{|c|}{ Marital status of caregivers } \\
\hline Married & $94(72.3)$ & $29(50.0)$ & $\chi^{2}=8.823 ; p=0.003$ \\
\hline Not Married & $36(27.7)$ & $29(50.0)$ & \\
\hline \multicolumn{4}{|c|}{ Couples' Discordance } \\
\hline Discordant couple & $32(35.5)$ & $20(24.7)$ & $X^{2}=3.275 ; p=0.195$ \\
\hline Not discordant & $58(64.4)$ & $61(75.3)$ & \\
\hline \multicolumn{4}{|l|}{ Family size } \\
\hline$<4$ & $31(23.7)$ & $21(35.6)$ & $\chi^{2}=2.912 ; p=0.09$ \\
\hline$\geq 4$ & $100(76.3)$ & $38(64.4)$ & \\
\hline \multicolumn{4}{|c|}{$\begin{array}{l}\text { Demise of family member to } \\
\text { HIV infection }\end{array}$} \\
\hline No & $78(60.5)$ & $29(49.2)$ & $\chi^{2}=3.035 ; p=0.219$ \\
\hline Yes & $51(39.5)$ & $30(50.8)$ & \\
\hline
\end{tabular}

FE - Fisher's Exact Test

\section{Discussion}

In the present study, a higher proportion of HIV-infected children were males. This observation agreed with the findings in a study conducted in Kano, Nigeria by Obiagwu et al. ${ }^{[8]}$ where male preponderance was reported among affected children. HIV infection in children mainly occurs through mother-to-child transmission and the gender predilection for HIV infection occurring through this route is unknown. [9] Partial HIV serostatus disclosure 
had been done in about one-third of the study population and in one-quarter, full serostatus disclosure had been achieved. A similarly low rate of serostatus disclosure was reported in Ghana by Hayfron-Benjamin et al.[10] In Nigeria, the disclosure rate to HIV-infected children has also been previously documented to be as low as $13.5 \%$ to $33 \%$.[11-14]

The mean age at serostatus disclosure in the current study was 11.1 years. This is slightly higher than the mean age reported in Tanzania and Ethiopia. [15,16] A similar mean age of 11.5 years was reported by Ubesie et al [12] in the south-eastern part of Nigeria. The mean age at disclosure in the current study was, however, higher than the reported value of 8.7 years by Brown and colleagues [11] in Ibadan, Nigeria. The involvement of children less than five years could account for the lower mean age observed in the study by Brown et al.[11]

Table IIb: Determinants of HIV sero-status disclosure

\begin{tabular}{|c|c|c|c|}
\hline & \multicolumn{2}{|c|}{ HIV Status Disclosure } & \multirow[t]{2}{*}{ Statistics } \\
\hline & No $(\%)$ & Yes (\%) & \\
\hline \multicolumn{4}{|c|}{$\begin{array}{l}\text { Demise of family member to } \\
\text { HIV infection }\end{array}$} \\
\hline No & $78(60.5)$ & $29(49.2)$ & $\chi^{2}=3.035 ; p=0.219$ \\
\hline Yes & $51(39.5)$ & $30(50.8)$ & \\
\hline \multicolumn{4}{|l|}{ Stage of Disease } \\
\hline 1 & $44(34.1)$ & $17(30.9)$ & ${ }^{*} \mathrm{FE}=11.388 ; \mathrm{p}=0.077$ \\
\hline 2 & $32(24.8)$ & $23(41.8)$ & \\
\hline 3 & $35(27.1)$ & $14(25.4)$ & \\
\hline 4 & $18(13.9)$ & $1(1.8)$ & \\
\hline \multicolumn{4}{|l|}{ TB Treatment } \\
\hline No & $99(72.8)$ & 35 (59.2) & $\chi^{2}=5.636 ; p=0.06$ \\
\hline Yes & $37(27.2)$ & $22(40.7)$ & \\
\hline \multicolumn{4}{|l|}{ Drug } \\
\hline First line & $113(85.6)$ & $46(78.0)$ & $\chi^{2}=1.798 ; p=0.407$ \\
\hline Second line & $19(14.4)$ & $13(22.0)$ & \\
\hline \multicolumn{4}{|l|}{ Viral suppression } \\
\hline Suppressed & $107(81.7)$ & 47 (79.7) & $\chi^{2}=0.326 ; p=0.849$ \\
\hline Not suppressed & $24(18.3)$ & $12(20.3)$ & \\
\hline
\end{tabular}

${ }^{*}$ FE - Fisher's Exact Test

Table III: Predictors of HIV status disclosure

\begin{tabular}{l|l|l}
\hline Variables & p-value & 95\% CI for EXP (B) \\
\hline Age of child & $0.001^{*}$ & 3.450 to 69.885 \\
Social Class & 0.138 & -.290 to -1.156 \\
Marital status of caregiver & $0.005^{*}$ & 1.301 to 4.641 \\
\hline
\end{tabular}

The caregivers of HIV-infected children who were yet to know their HIV serostatus planned disclosure at the mean age of 14.2 years in the current study. Bearing in mind the importance of disclosure of HIV serostatus to care, there is a need for more strategic efforts that will encourage age-related serostatus disclosure as well as address the hindrances to disclosure. 
Parents were mostly responsible for the disclosure in the present study. This is similar to the report by Naidoo et al [17] in South Africa. HIV serostatus disclosure had a similar outcome irrespective of who was involved in the disclosure process. This shows that the disclosure of serostatus to HIV-infected children may be done by caregivers who know how to. Studies have shown difficulties in serostatus disclosure by both parents and health care providers. [18,19] With the adoption of the guidelines on serostatus disclosure, all the participants involved in the care of HIV infected children should be able to handle serostatus disclosure in children.

Positive impacts of serostatus disclosure in the current study included better antiretroviral drug adherence, a better relationship with the caregiver and less questioning. Improvement in drug adherence following disclosure is one of the most consistent positive impacts reported in previous studies. [11,20-23] Adherence to antiretroviral medications is crucial to the attainment of treatment goals in paediatric HIV. Therefore, improvement in the disclosure rate may also contribute to the achievement of the required goals.

In the present study, about one-third of the children with serostatus disclosure had negative responses such as anger, withdrawal, and sadness. Negative responses following serostatus disclosure have been previously documented. [24,25] These negative impacts have been realised to be inconsequential compared to the benefits. [26] In the present study, the negative responses lasted mostly within a month. There is a need to encourage caregivers on the significant benefits of serostatus disclosure compared to the negative responses which are mostly transient.

Maturity in age and understanding was the major reason for serostatus disclosure in the present study. Frequent questioning, the demise of a sibling and poor drug adherence were prominent reasons for serostatus disclosure in the present study. The caregivers' perception of affected children being too young, stigmatization and lack of how to disclose, mostly accounted for the failure of serostatus disclosure. In some previous studies, similar barriers to serostatus disclosure have been reported. [22,27] Stigmatization is a major social problem faced by HIV-infected individuals. It is a major hindrance to the care and disclosure of HIV serostatus, hence, it requires more education of the populace. The lack of knowhow was the third leading reason for nondisclosure of serostatus in the current study. There is a need for more parental education and support on disclosure of their wards' HIV serostatus.

The need for serostatus disclosure at a stage in life was unanimously accepted by the healthcare workers. The majority of healthcare workers in the care of HIV-infected children believed disclosure of serostatus to affected children should be carried out from the age of twelve years while over a quarter of them had no idea of the age disclosure should be done. This observation revealed the need for training of health care providers on how to disclose HIV serostatus to affected children. This requirement for training was also requested by almost threequarters of the participants in the current study. Lack of training was identified as a barrier to serostatus disclosure by Kalembo et al. [19] WHO recommends training for healthcare providers and provides counselling guideline on serostatus disclosure. ${ }^{[28]}$

In the present study, children aged ten years and above were more likely to know their HIV serostatus compared to the younger age group. This is in keeping with the findings in some previous studies. ${ }^{111,15,16]}$ The caregivers within the low social class were more forthcoming with 
the disclosure of the HIV status to their wards compared to those in high social class. This is in keeping with the finding reported by Ubesie et al. ${ }^{[12]}$ and also in keeping with the report that uneducated parents had a higher rate of serostatus disclosure compared with educated parents. In contrast, Nzota et al. [29] in a Tanzanian study reported a higher rate of serostatus disclosure to children of higherincome earners than those with lower monthly income. The need for dependence on relations and the extended family system for supports, which is commoner in the lower social classes, could account for the less inhibition over divulging of serostatus of affected children.

Orphans, children of separated parents and children of single parents were more likely to know their HIV serostatus than those whose parents lived together. Higher likelihood of disclosure to orphaned children was also reported by Negese et al. [16] The finding of a higher rate of serostatus disclosure to children with single parents observed in the current study, had earlier been reported by Kodyalamoole et al. [27] in India. Single parenthood and orphanhood are liable to financial challenges and this may account for the higher rate of serostatus disclosure in these groups of people. Dependence on others for supports as well as incentives commonly provided in the Adolescent Clinic at the study centres (for which serostatus disclosure is a prerequisite for enrolment) could account for the higher rate of serostatus disclosure in these individuals with the likelihood of financial dependence. Sero-status disclosure was more likely, though not in a significant proportion, among children with a history of the demise of a family member unlike its significant determinant for serostatus disclosure as reported by Negese et al. [16]

A non-significantly lower proportion of discordant couples have disclosed their ward's
HIV serostatus to them compared to seropositive couples. The rate of disclosure of HIV status among non-discordant couples is low in Nigeria. ${ }^{[30]}$ This is expected to reflect on the serostatus disclosure of children in these circumstances. As observed in the present study, independent determinants of serostatus disclosure included the age of the child and the marital status of the caregiver. Children with single parents were more likely to know their HIV serostatus compared with those with married parents who lived together. This is similar to the finding of a higher rate of serostatus disclosure to children living with their mothers only by Tsuzuki et al. [31]

\section{Conclusion}

Overall, the serostatus disclosure rate to a population of HIV-infected Nigerian children is low. The disclosure by all individuals involved in the care of affected children has similar effects. Children aged ten years and above and with unmarried parents are more likely to know their HIV serostatus compared with younger age groups or those with married parents. There is a need for training and support for parents on the disclosure of HIV serostatus. Knowledge of age-appropriate disclosure for younger children with HIV infection is required. Routine training of healthcare personnel in the care of affected children as a strategic tool for the increase in the rate of HIV serostatus disclosure to affected children cannot be overemphasized.

Acknowledgment: All the healthcare personnel, HIVinfected children and their primary caregivers who participated in the study.

Authors' Contributions: AMO, AMA, and OOA gathered the data while AMO analysed and interpreted the data. AMO, UPO, AAB drafted the 
manuscript. All the authors approved the final version of the manuscript.

Conflict of Interest: None.

Funding: Self-funded.

Publication History: Submitted 19 July 2019; Revised 14 September 2019; Accepted 25 September 2019.

\section{References}

1. Deeks SG, Lewis SR, Havlir DV. The end to AIDS: HIV infection as a chronic disease. Lancet 2013; 382(9903): 1525-1533.

2. Atuyambe LM, Ssegujja E, Ssali S, Tumwine C, Nekesa N, Nannungi A, et al. HIV/AIDS disclosure increases support, behavioural change and, HIV prevention in the long term: a case for an urban clinic, Kampala, Uganda. BMC Health Services Res 2014; 14: 276.

3. World Health Organization. WHO guidelines on HIV disclosure counselling for children up to 12 years of age. 2011. www.who.int/hiv/topics/vct/en/index.ht $\underline{\mathrm{ml}}$

4. GBD 2013 Mortality and Causes of Death Collaborators 2015. Global, regional and national age-sex specific all-cause and causespecific mortality for 240 causes of death, 1990-2013: a systematic analysis for the global burden of disease study 2013. Lancet 2015; 385: 117-171.

5. UNICEF Annual Results 2014. HIV and AIDS.

https://www.unicef.org/publicpartenrships /files/2014_Annual_Reports_HIV_and_AID S.

6. WHO. Guideline on HIV disclosure counselling for children. 2011. http://apps.who.int/iris/hamdle/10665/44 777. Accessed 5th December 2018
7. Ogunlesi TA, Dedeke IOF, Kuponiyi OT. Socioeconomic classification of children attending Specialist Paediatric Centres in Ogun State, Nigeria. Niger Med Pract 2008; 54(1): 21-25.

8. Obiagwu PN, Hassan-Hanga F, Ibrahim. Paediatric HIV in Kano, Nigeria. Niger J Clin Pract.2013; 16: 521-525.

9. Taha TE, Nour S, Kumwenda NI, Broadhead RL, Fiscus SA, Kafulafula G, et al. Gender differences in perinatal HIV acquisition among African infants. Paediatrics 2005; 115(2): e167-e172.

10. Hayfron-Benjamin A, Obiri-Yeboah D, AyisiAddo S, Siakwa PM, Mupepi S. HIV diagnosis disclosure to infected children and adolescents; challenges of family caregivers in the Central region of Ghana. BMC Paediatr 2018; 18: 365.

11. Brown BJ, Oladokun RE, Osinusi $\mathrm{K}$, Ochigbo S, Adewole IF, Kanki P. Disclosure of HIV status to infected children in a Nigerian HIV care programme. AIDS Care 2011; 23(9): 1053-1058.

12. Ubesie AC, Iloh KK, Emodi IJ, Ibeziako NS, Obumneme-Anyim IN, Iloh UN, et al. HIV status disclosure rate and reasons for nondisclosure among infected children and adolescents in Enugu, Southeast, Nigeria. SAHARA-J 2016; 13(1): 136-141.

13. Ikpeme EE, Dixon Umo DT. Disclosure of HIV diagnosis to infected children receiving care in University of Uyo Teaching Hospital, Uyo, Nigeria. J AIDS HIV Res 2016; 8(7): 9399. 
14. Orji ML, Onyira NB, Onwe OE. Status disclosure in HIV infected children in Abakaliki, Ebonyi State, Southeast, Nigeria. J Nepal Paediatr Soc 2017; 37(3): 244-248.

15. Mumburi LP, Hamel BC, Philemon RN, Kapanda GN, Msuya LJ. Factors associated with HIV-status disclosure to HIV-infected children receiving care at Kilimanjaro Christian Medical Centre in Moshi, Tanzania. Pan Afr Med J 2014; 18: 50. doi:10. 11604/pamj. 2014.18.50.2307.

16. Negese D, Addis K, Awoke A, Birhanu Z, Muluye D, Yifru S, et al. HIV-positive status disclosure and associated factors among children in North Gundar, Northwest Ethiopia. ISRN AIDS 2012; Article ID 485720.

17. Naidoo GD, McKerrow NH. Current practices around HIV disclosure to children on highly active antiretroviral therapy. South Afr J Child Health 2015; 9(3): 85-88.

18. Mandalazi P, Bandawe C, Umar E. HIV disclosure: a parental dilemma in informing HIV infected children about their HIV status in Malawi. Malawi Med J 2014; 26(4): 101104.

19. Kalembo FW, Kendall GE, Ali M, Chimwaza AF. Healthcare workers' perspectives and practices regarding the disclosure of HIV status to children in Malawi: a crosssectional study. BMC Health Serv Res 2018; 18(540): 1-10.

20. Bulali RE, Kibusi SM, Mpondo BCT. Factors associated with HIV status disclosure and its effect on treatment adherence and quality of life among children 6-17 years on antiretroviral therapy in Southern Highlands zone, Tanzania: unmatched case-control study. Int J Paediatr .2018; Article ID 8058291.

21. Nichols JS, Kyriakides TC, Sampson A, Renner L, Lartey M, Seaneke OA, et al. High prevalence of non-adherence to antiretroviral therapy among undisclosed HIV-infected children in Ghana. AIDS Care 2018; 31(2): 1-10.

22. Oberdorfer P, Puthanakit T, Louthrenoo O, Charnsil C, Sirisanthana V, Sirisanthana T. Disclosure of HIV/AIDS diagnosis to HIVinfected children in Thailand. J Paediatr Child Health 2006; 42(5): 283-288.

23. Bikaako-Kajura W, Luyirika E, Purcell DW, Downing J, Kaharuza F, Mermin J, et al. Disclosure of HIV status and adherence to daily drug regimens among HIV-infected children in Uganda. AIDS Behav 2006; 10 (Supl4): S85-S93.

24. Vreeman RC, Scanlon ML, Mirangi A, Turissini M, Ayaya SO, Tenge C, et al. A cross-sectional study of disclosure of HIV status to children and adolescents in Western Kenya. PLoS ONE 9(1): e86616.doi10.1371/journal.pone.0086616.

25. Binagwaho A, Murekatete I, Rukundo A, Mugwaneza P, Hinda R, Lyambabaje A, et al. Factors associated with disclosure of HIV positive children in Rwanda. RMJ 2012; 69(3): 9.

26. Krauss BJ, Letteney S, De Baets A, Baggaley $\mathrm{R}$, Okero FA. Disclosure of HIV status to HIV-positive children 12 and under: A systematic cross-national review for health and well-being. Vuln Child Youth Stud 2013; 8(2): 99-119.

27. Kodyalamoole NK, Badiger S, Kiran NU, Dodderi SK, Rewari BB. Pattern of paediatric HIV status disclosure in coastal Karnataka. Indian J Med Res 2018; 147(5): 501-506.

28. WHO. Training. https://www.who.int/hiv/topics/vct/toolk it/components/training/en/index4.html. Accessed 10 th February 2019.

29. Nzota MS, Matovu JKB, Draper HR, Kisa R, Kiwanuka SN. Determinants and processes of HIV status disclosure to HIV-infected 
children aged 4 to 17 years receiving HIV care services at Baylor College of Medicine Children's Foundation, Tanzania, Centre of Excellence (COE) in Mbeya: a cross-sectional study. BMC Paediatr 2015; 15: 81.

30. Ebuenyi ID, Ogoina D, Ikuabe PO, Harry TC, Inatimi O, Chuhwueke OU. Prevalence pattern and determinants of disclosure of
HIV status in an antiretroviral therapy clinic in the Niger Delta region of Nigeria. Afr J Infect Dis 2014; 8(2): 27-30

31. Tsuzuki S, Ishikawa N, Miyamoto H, Dube C, Kayama N, Watala J, et al. Disclosure to HIV-seropositive children in rural Zambia. BMC Paediatr 2018; 18: 272.

\section{(c) (1) (8) EY NC}

This is an Open Access document licensed for distribution under the terms and conditions of the Creative Commons Attribution License (http://creativecommons.org/licenses/by-nc/4.0). This permits unrestricted, non-commercial use, reproduction and distribution in any medium provided the original source is adequately cited and credited. 